\title{
Perforin deficiency and susceptibility to cancer
}

\author{
AJ Brennan ${ }^{1,2,5}$, J Chia ${ }^{1,5}$, JA Trapani ${ }^{1,3}$ and I Voskoboinik ${ }^{*, 1,4}$
}

Cytotoxic lymphocytes (CLs) are the killer cells that destroy intracellular pathogen-infected and transformed cells, predominantly through the cytotoxic granule-mediated death pathway. Soluble cytotoxic granule components, including pore-forming perforin and pro-apoptotic serine proteases, granzymes, synergize to induce unscheduled apoptosis of the target cell. A complete loss of CL function results in an aggressive immunoregulatory disorder, familial hemophagocytic lymphohistiocytosis, whereas a partial loss of function seems to be a factor strongly predisposing to hematological malignancies. This review discusses the pathological manifestations of $\mathrm{CL}$ deficiencies due to impaired perforin function and describes novel aspects of perforin biology.

Cell Death and Differentiation (2010) 17, 607-615; doi:10.1038/cdd.2009.212; published online 15 January 2010

Cytotoxic T lymphocytes (CTLs) and natural killer (NK) cells, collectively called cytotoxic lymphocytes (CLs), kill virusinfected and transformed cells through a number of contactdependent mechanisms. ${ }^{1,2}$ Engagement of death receptors by membrane-bound members of the TNF superfamily of death ligands is critical for maintaining lymphoid homeostasis in the host. By contrast, studies of gene deficiencies indicate that defects of the granule exocytosis pathway result in a failure to eliminate infected cells or those that pose a risk of subsequent malignancy. Although cytotoxic granules contain diverse toxins that together contribute to apoptosis induction, this review will deal exclusively with the critical role of the pore-forming protein perforin (PRF) as an essential enabler of target-cell apoptosis, and its more recently described role as a potential 'extrinsic' tumor suppressor.

Perforin is a $67-\mathrm{kDa}$ pore-forming protein that is stored and released from the secretory granules (SGs) of CLs along with a number of pro-apoptotic serine protease granzymes that display broad substrate specificities. ${ }^{3}$ Following exocytic release, PRF and the granzymes are exposed to the neutral $\mathrm{pH}$ and calciumrich environment of the immune synapse. ${ }^{4}$ After binding calcium through their $\mathrm{C} 2$ domains, PRF monomers acquire the ability to bind generic lipids in the target cell membrane, ${ }^{5}$ and then coalesce into large transmembrane pores that permit the granzymes to access key death substrates in the cytosol. ${ }^{6-8}$ Although the diverse apoptotic pathways triggered by granzymes have been extensively studied and are now understood in considerable detail, it is only of late that insights into the molecular and cellular functions of PRF have been even partly addressed.
In this review, we will re-examine the pathological consequences of PRF deficiency, both in mice and humans. In doing so, important differences in PRF biology between these species will be described. We will discuss the pathogenic effect of a number of recently described missense mutations of human PRF. In particular, although the complete absence of PRF function typically results in an aggressive, fatal immunoregulatory disorder of early childhood known as familial hemophagocytic lymphohistiocytosis $(\mathrm{FHL}),{ }^{9}$ we have recently discovered that partial loss of $\mathrm{PRF}$ function is strongly associated with $\mathrm{FHL}$ and/or an array of hematological malignancies later in childhood or in adolescence. ${ }^{10}$ The latter findings have specific significance for our understanding of the role of the immune system in detecting and destroying cancer cells before clinical presentation, a process also known as cancer immune surveillance.

\section{Perforin Biology}

In contrast to granzymes, PRF is represented in mammals and marsupials by a single gene, $P R F 1$. In mammals, $P R F 1$ is uniquely expressed in CLs, although some reports also suggest its expression in regulatory $T$ cells. The regulation of PRF1 gene expression is complex and has been revealed only recently in an elegant study by Lichtenheld and coworkers. ${ }^{11}$ The study showed a Locus Control Region that regulates cell lineage- and activation signal-specific expression of PRF1. Such a heterochromatin-dependent regulation may enable exogenous stimuli or endogenous transcription-

\footnotetext{
${ }^{1}$ Cancer Immunology Program, Peter MacCallum Cancer Centre, East Melbourne, Victoria 3002, Australia; ${ }^{2}$ Department of Pathology, The University of Melbourne, Victoria 3052, Australia; ${ }^{3}$ Department of Microbiology and Immunology, The University of Melbourne, Victoria 3052, Australia and ${ }^{4}$ Department of Genetics, The University of Melbourne, Victoria 3052, Australia

*Corresponding author: I Voskoboinik, Cancer Immunology Program, Peter MacCallum Cancer Centre, St Andrews Place, East Melbourne, VIC 3002, Australia. Tel: + 6139656 3725; Fax: + 6139656 1411; E-mail: ilia.voskoboinik@ petermac.org

${ }^{5}$ These two authors are joint first authors.

Keywords: cytotoxic lymphocytes; lymphoma; leukemia; granzyme; FHL

Abbreviations: CTL, cytotoxic T lymphocytes; NK, natural killer cells; CL, cytotoxic lymphocytes; PRF, pore-forming protein perforin; FHL, familial hemophagocytic lymphohistiocytosis; MACPF, membrane attack complex/perforin; SG, secretory granules; CDC, cholesterol-dependent cytolysins

Received 10.9.09; revised 16.11.09; accepted 27.11.09; Edited by D Granville; published online 15.1.10
} 
regulating factors to induce $P R F 1$ transcription in other cell types. Indeed, there are several lines of evidence for UV radiation acting through the epidermal growth factor receptor to induce the expression of PRF (and granzyme B) in cultured keratinocytes, thus enabling the irradiated cells to kill 'target' cells. ${ }^{12,13}$ However, the mechanisms responsible for synapse formation or intercellular contact and the triggering event for PRF and granzyme release in these cells remain unclear.

Perforin was first discovered in the year 1983 and cloned from an expression library in the year 1988 through anti-complement C9 antibody cross-reactivity. ${ }^{14-19}$ Sequence comparison revealed a striking similarity between the two proteins within a short region in their middle part, which was named the 'membrane attack complex/perforin' (MACPF) domain. 16,20,21 Initial characterization of PRF revealed that its pore-forming activity at the phospholipid membrane was calcium dependent. $^{22,23}$ Paradoxically, the CLs could synthesize and store large amounts of PRF without any apparent detrimental consequence, even though the endoplasmic reticulum seems to provide $\mathrm{Ca}^{2+}$ concentrations suitable for membrane binding and pore formation. Granzymes and other toxic proteases are synthesized as zymogens and are typically activated only on reaching lysosome-like SGs; ${ }^{24,25}$ in the cytosol of CLs, 'escaped' granzymes can be irreversibly inhibited by serpins (for example, human $\mathrm{PI}-9$ or mouse SPI-6). ${ }^{26-29}$ However, there does not seem to be any naturally occurring inhibitor for PRF. This paradox gave rise to various hypotheses, including receptor-dependent PRF activity. Alternatively, one might propose that a cell should use nongeneric resources to regulate PRF expression and manage its toxicity. Indeed, the only study addressing this intriguing issue suggested that PRF glycosylation in the endoplasmic reticulum and the extreme $\mathrm{C}$-terminal peptide prevent $\mathrm{Ca}^{2+}$ binding to the $\mathrm{C} 2$ domain, thus inhibiting the first essential step in pore formation - membrane binding. It has been hypothesized that a putative protease cleaves the extreme C-terminal peptide together with its $\mathrm{N}$-glycosylation moiety in the SGs, thereby activating PRF. ${ }^{4}$ However, a protease and direct evidence for the essential role of PRF cleavage are yet to be shown. Irrespective of the mechanism, the acidic environment of SGs prevents the PRF C2-domain from binding $\mathrm{Ca}^{2+} .{ }^{5}$ Only after reaching the immunological synapse with its presumably neutral $\mathrm{pH}$ does PRF acquire the ability to bind $\mathrm{Ca}^{2+}$ and initiate pore formation ${ }^{5}$ (Figure 1 ).

The three dimensional structure of PRF and any other MACPF proteins ( $>500$ are currently known or predicted), has been an enigma for well over two decades, mainly due to difficulties in expressing sufficient amounts for structural studies. ${ }^{30}$ Furthermore, the lack of sequence similarity with other structurally characterized proteins also delayed progress. However, in the year 2007-2008, three independent studies arrived at the same remarkable conclusion: despite sharing minimal amino acid sequence similarity, mammalian and other MACPF proteins are structurally related to bacterial cholesterol-dependent cytolysins (CDCs) and operate by an analogous mechanism. ${ }^{31-33}$ These studies opened new horizons in studying MACPF proteins, as their membership with a large family of well-characterized proteins has finally been identified. Despite these advances, major milestones in MACPF research are yet to be reached, namely, the crystal

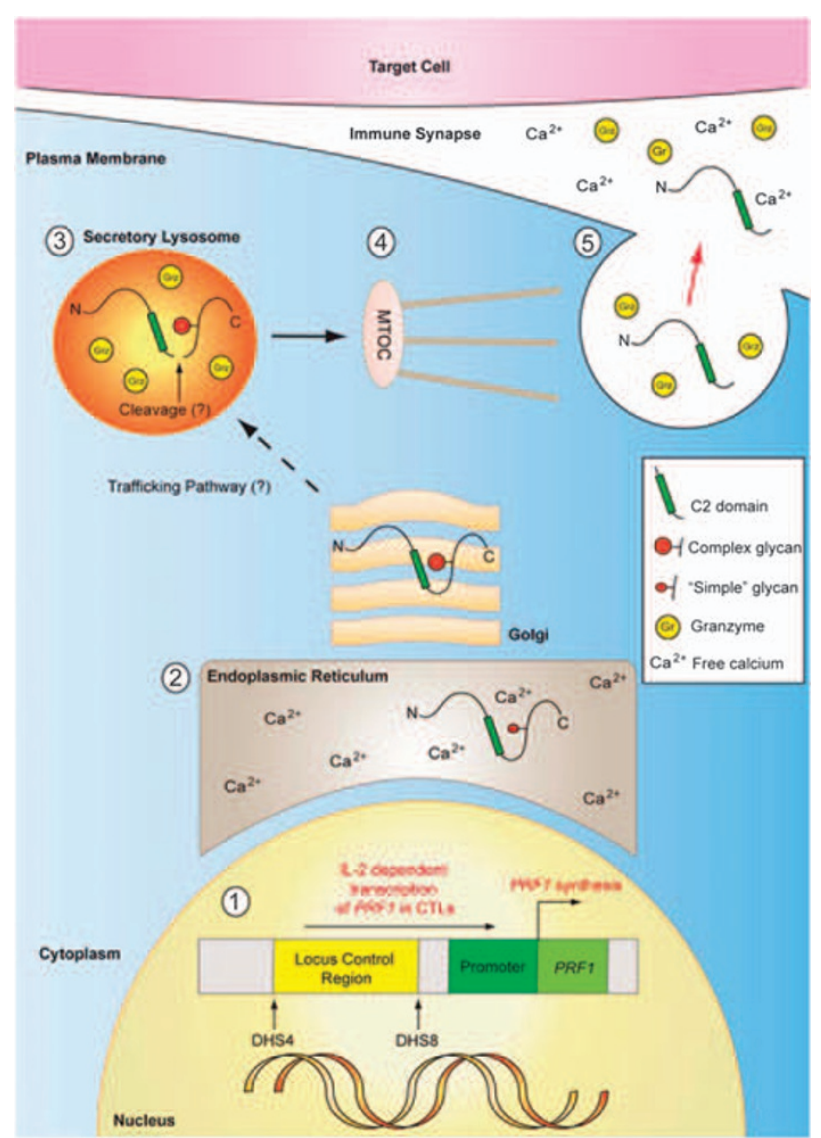

Figure 1 Regulation of $P R F 1$ gene expression and post-translation activation of perforin function. (1) The active chromatin domain of PRF1 includes an $\sim 150 \mathrm{~kb}$ long DNA domain that is regulated by the activated Locus Control Region (LCR), DHS4-DHS8, in CTLs and NK cells (adapted from Trapani JA and Voskoboinik ${ }^{94}$ ). (2) It has been hypothesized that binding and activation of the high-affinity $\mathrm{Ca}^{2+}$-dependent phospholipid C2 domain of PRF is prevented in the ER (which has high $\mathrm{Ca}^{2+}$ and neutral pH) by the extreme C-terminus (last $12-20$ a.a.). (3) The extreme $\mathrm{C}$-terminus is proteolytically cleaved in the acidic SGs, which is thought to liberate the $\mathrm{Ca}^{2+}$-binding moiety and produce a form of PRF that remains nonfunctional until the $\mathrm{pH}$ becomes neutral in the context of the immune synapse. (4) Recognition of target cell surface receptor molecules triggers the polarization of the microtubule organizing center (MTOC) towards the immune synapse, followed by vectorial trafficking of secretory granules towards the synaptic cleft. (5) The granules dock to the plasma membrane, fuse and exocytose PRF and pro-apoptotic serine proteases granzymes (Grz) into the immune synapse in which PRF forms a transmembrane pore (not shown) to allow granzyme internalization by a yet to be identified mechanism and deliver the 'kiss of death'

structure of a pore-forming MACPF protein, the mechanism of pore formation and the structure of a pore.

The effect of recent discoveries was the fall of previous dogma that the central, most conserved domain shared by PRF and the complement components represented two amphipathic $\alpha$-helices that formed the transmembrane region of the pore. ${ }^{21}$ Rather, it is now unequivocally clear that this region forms an interface between adjacent PRF monomers within an oligomeric pore. ${ }^{34}$ Importantly, this discovery indirectly assigned the membrane-spanning role to two alternative helical domains $\mathrm{TMH} 1$ and $\mathrm{TMH} 2$ that unfold into two membrane-spanning $\beta$-hairpins. ${ }^{31-33}$ This provided 
further support for the ancestral relationship between CDC and MACPF protein families.

\section{Perforin and Immune Homeostasis in Mice}

The fundamental basis of the SG death pathway is the synergy between its components, PRF and granzymes. These molecules have distinct roles, wherein transmembrane PRF pores serve as entry points for proteases into the cytosol of the target cell allowing granzymes to initiate various apoptotic pathways. Although granzymes can internalize independently of PRF, when sequestered in the lumen of endocytic vesicles, they have no access to cytosolic substrates and remain innocuous. Earlier and recent studies (described above) have clearly indicated that PRF pores are sufficiently large (up to $200 \AA$ diameter) to allow multiple granzyme molecules to enter the cells. However, it is still debated whether PRF and granzymes co-internalize into an endocytic compartment, which is subsequently lysed in the cytosol, or whether the influx of granzymes occurs through disrupted plasma membrane. Regardless, the essential role of PRF in the SG death pathway is undisputable and remains the cornerstone of CL cytotoxicity.

Owing to the essential role of PRF in the delivery of granzymes to the target cell, $\mathrm{PRF}^{-1-}$ mice have become a classic model of CL immunodeficiency, and show impaired immune surveillance of viruses and spontaneous, induced and transplanted cancers. However, here we will emphasize only two aspects of PRF biology in mice that are of particular significance for understanding the role of PRF and CLs in humans. $^{35,36}$

Although unchallenged PRF-deficient mice would be expected to be prone to viral infections, they remain healthy when housed in standard facilities. Only when challenged with mouse pathogens such as lymphocytic choriomeningitis virus (LCMV) or ectromelia, did the mice rapidly succumb to infections. $^{37-40}$ In response to LCMV, PRF-deficient mice developed a syndrome highly reminiscent of human hemophagocytic lymphohistiocytosis (discussed below). ${ }^{41}$ By contrast, loss of individual granzymes, such as mouse granzyme A or B, had no significant effect on the suppression of tested viral pathogens apart from ectromelia, and the absence of both granzymes was needed to show marked susceptibility to these pathogens. ${ }^{6,42-44}$ Together, the combined substrate specificity of granzymes offers CLs a broad spectrum of cytotoxic mechanisms that provide resistance to immunogenic challenges. ${ }^{42-46}$ For this reason, in the context of genetic models, only the total loss of granzyme function can be compared with PRF deficiency with respect to the function of CLs. These and other studies have clearly assigned the undisputable role of 'gatekeeper' to PRF, whereas granzymes appear to have evolved to allow adaptation to ever-evolving viral challenges. ${ }^{42-46}$ Accordingly, analysis of granzyme sequences in wild mice revealed extensive geographic heterogeneity, but in all inbred strains tested, they were almost identical. ${ }^{47}$ This apparent discrepancy is explicable in that all commonly used inbred strains originated more than a century ago from a single female, as determined by studies of mitochondrial DNA. By contrast, PRF was remarkably conserved in the wild mice (our unpublished observations), supporting the notion of a single-function generic protein. Consistent with this, only two 'silent' PRF polymorphisms and one amino acid substitution have been identified in large-scale human population studies to affect more than $1 \%$ of the population. ${ }^{47}$

Earlier research convincingly showed that $P R F 1^{-1-}$ mice were up to 1000-times more susceptible than immunocompetent animals to transplanted and induced malignancies, predominantly of hematological origin. ${ }^{36,48-56}$ These findings are broadly consistent with the theory of tumor immune surveillance first proposed by Macfarlane Burnett and Lewis Thomas over 50 years ago. However, the most intriguing observation, with direct implications for immune surveillance of tumors in humans, was that the majority of unchallenged $\mathrm{PRF}^{-1-}$ mice developed highly aggressive disseminated $\mathrm{B}$ cell lymphoma beyond the age of 12 months. ${ }^{36}$ Importantly, all the tumors were $\mathrm{MHC}$ class I positive meaning they could be rejected by immunocompetent $\mathrm{CD}^{+}$CTLs, as shown by transplantation into syngeneic $P R F 1^{+/+}$mice. This observation was critical for understanding the role of PRF in protection against spontaneous malignancy. However, it is unclear why B-cell lymphomas dominate the spectrum of cancers, with few carcinomas and sarcomas noted.

\section{Perforin Deficiency in Humans}

Functional perforin is also essential for $\mathrm{CL}$ function in humans, as detrimental mutations in PRF1 lead to a devastating disease of immune homeostasis, type $2 \mathrm{FHL}$ (FHL2), ${ }^{9}$ accounting for $30-60 \%$ of all $\mathrm{FHL}$ cases $^{58}$ and affecting $\sim 1$ in 90000 live births. ${ }^{59} \mathrm{FHL}$ results from dysregulated pathways that govern the termination of immune/inflammatory responses, implicating the SG death pathway as a critical regulator of CL cytotoxicity in humans. ${ }^{60}$ The hallmark feature of $\mathrm{FHL}$ is the hyper-activation of antigen-presenting cells (macrophages and tissue histiocytes) and CD8 ${ }^{+} \mathrm{T}$ cells. This uncontrolled activation results in the proliferation and accumulation of $\mathrm{T}$ cells in certain inflammatory sites, particularly in the central nervous system (CNS), and prolonged elevation of multiple proinflammatory cytokines (chronic hypercytokinemia), which is indicative of impaired CL function and the failure of normal immune downregulation. ${ }^{60,61}$

Perforin deficiency is not the only cause of FHL. Mutations in UNC13D are responsible for type $3 \mathrm{FHL}$ (FHL3). ${ }^{62}$ This gene encodes Munc13-4, a member of the ubiquitous family of Munc proteins, which have an important role in subcellular trafficking. Mutations in Munc13-4 result in the loss of SG priming at the plasma membrane and their inability to exocytose PRF and granzymes into the immunological synapse. $^{63}$ Importantly, as both Munc13-4 and PRF are uniquely expressed in hematopoietic cells, their loss of function does not have a systemic effect, and bone marrow transplantation is therefore a potentially life-saving therapy for FHL patients.

Recently, mutations in the STX11 gene encoding a t-SNARE protein, syntaxin 11 (STX11), and the partner protein Munc18-2 (STXBP2) ${ }^{64,65}$ have also been associated with type 4 and 5 FHLs, respectively. Although FHL2 and FHL3 phenotypes are easily identifiable through the loss of IL-2-stimulated peripheral blood mononuclear cell (LAK) 
cytotoxicity, FHL4 and FHL5 patients display a differential phenotype, in which only NK cells appear to be functionally impaired. ${ }^{66}$ Consistent with the role of SNAREs in subcellular trafficking, unstimulated NKs from FHL4 and FHL5 patients had no cytotoxic activity and were unable to degranulate. ${ }^{64,65}$ However, IL-2 stimulation considerably restored cytotoxicity. ${ }^{66}$ These observations are significant as they are the first to implicate NK cell deficiency as a specific trigger for FHL, although the mechanism is not fully understood. ${ }^{66}$ One possible explanation is that NK cells might regulate immune homeostasis through killing dendritic cells or regulating CTL proliferation. It also remains unclear why IL-2 restores killing in syntaxin 11-deficient NK cells. However, as a result, the FHL4 phenotype is relatively mild and the disease rarely has CNS symptoms, as opposed to FHL2 and FHL3.

\section{Genetics and Geoepidemiology of FHL}

There are several clear epicenters of PRF1-associated FHL, based on some common mutations originating specifically in Japan, Central Africa or the Eastern Mediterranean region, with the majority of cases reported in Italy, Turkey and among Europeans of North African descent. ${ }^{58,67-69}$ For example, the W374X mutation of PRF1 is common among patients of Turkish descent, a frameshift mutation 50delT leading to premature termination of PRF is virtually unique to patients of Central African descent ${ }^{70}$ and the frameshift 1090.91delCT and 207delC originated from and are unique to SouthWestern Japan. ${ }^{67,71}$ A number of disease incidents were also reported in other parts of Europe, but many of these patients were of Mediterranean origin. A significant proportion of the patients come from consanguineous marriages and as a result are homozygous for disease-causing mutations. In contrast to FHL2, FHL3 seems to be ethnicity independent, whereas FHL4 has been thus far identified only within Turkish families. ${ }^{68}$

Within the past generation, the survival from early-onset FHL has improved significantly, due to an increased understanding of the underlying pathophysiology, advances in supportive care and wide availability of bone marrow reconstitution through transplantation. As a result, the 5-year survival has improved to over $50 \%$. The use of cytotoxic drugs in the acute phase of disease has also markedly improved the outlook by reducing the numbers of proliferating antigenpresenting cells directly. ${ }^{60}$

\section{A91V Polymorphism of Perforin}

The A91V allele is the most common variant found in the Caucasian population, resulting from the nucleotide substitution $\mathrm{C} 272 \mathrm{~T}$ in exon 2. It has been reported at a relatively high frequency of between 3 and $17 \%$ in Caucasian subjects. ${ }^{72-74}$ Interestingly, A91V seems to be at a very low frequency of $0.7 \%$ in African-American subjects, ${ }^{72}$ Sub-Saharan Africans ${ }^{75}$ and there are no reported cases of the polymorphism in Japan, thus reinforcing the Mediterranean origin of the mutation. However, the predicted frequency of A91V homozygosity ( $\sim 1 / 700$ individuals, on the basis of occurrence of the homozygotes in various population studies) is vastly in excess of the frequency of FHL2 cases, that is, $0.002 \%$
(1:50000 live births); this level of occurrence suggests a neutral polymorphism. Concordantly, A91V homozygosity has been found in several asymptomatic (at the time of genotyping) individuals. Nevertheless, several cases of FHL have been linked to A91V. In most of these patients, A91V was either inherited in the homozygous state or was the only functional allele present, as the second allele of PRF1 had either a frameshift or inactivating missense mutation (all these cases are summarized in Chia et $a l^{10}$ ).

Importantly, A91V has also been proposed to predispose to various types of cancer, including $B$ and T-cell lymphoma, ${ }^{76}$ acute lymphoblastic leukemia ${ }^{73}$, anaplastic large cell lymphoma (ALL), ${ }^{77}$ and to Dianzani lymphoproliferative disease. ${ }^{78}$ Although the numbers of cancer-afflicted individuals were small, A91V was either inherited in the homozygous state or more commonly with one wild-type allele. This was an unexpected observation as it has been well documented that PRF deficiency leading to serious clinical consequence is an autosomal recessive event. As a counterbalance to these findings, a much larger epidemiological study found no significant difference between the frequency of A91V allele in ALL patients compared with control subjects, but an increased incidence of the mutation was found in a small number of BCR-ABL-positive ALL patients. ${ }^{72}$ So can A91V mutation contribute to a disease? This was clearly an important question, and several research groups went on to investigate the effect of the mutation in various experimental systems.

Unusually, for such a controversial area of research, a consensus has been reached: $A 91 \mathrm{~V}$ is a functionally impaired mutant protein, not a neutral polymorphism. The A91V mutation affects PRF folding and stability within the effector cell, and as a result greatly reduces its intrinsic cytolytic activity. ${ }^{79-81}$ However, within the environment of PRF-deficient CTLs, the mutant recovered $30-50 \%$ of the wild-type PRF activity. ${ }^{80}$ Interestingly, in vitro A91V also

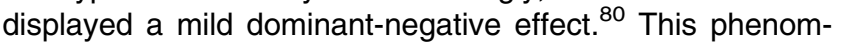
enon is potentially very important, as unlike most other naturally occurring PRF mutants that are almost completely degraded in the effector cell and cannot inhibit wild-type PRF function, the steady-state level of A91V expression is significant. Taken together, the combination of functional and clinical observations suggests that when co-inherited with the normal allele, A91V is unlikely to have a pathological role. However, if expressed in excess of the wild-type PRF, its negative impact on CL function may predispose to disease, such as the various hematological cancers mentioned above.

\section{Perforin Deficiency and Human Cancer}

Environmental or common microbial agents are thought to trigger FHL, typically in infancy. ${ }^{82}$ However, it has recently become evident that the first significant incidence of $\mathrm{FHL}$ can also occur in adolescence or adulthood. ${ }^{83,84}$ The most detrimental PRF1 mutations associated with minimal or no protein expression invariably present during early infancy, with a mean age of onset of 2 months. ${ }^{3,69}$ If untreated, this form of $\mathrm{FHL}$ is always fatal within a few months or even weeks. By contrast, compound heterozygous PRF1 missense muta- 
tions are predominantly detected in older patients ${ }^{3,69}$ and encode partially active PRF, which might enable patients to survive for a significant period of time before developing FHL. ${ }^{10}$

We have been interested in addressing the still highly contentious issue of whether the immune system contributes to immune surveillance of cancer in humans. Traditional epidemiological approaches to studying PRF deficiency and cancer susceptibility are virtually impossible, ${ }^{85}$ as bi-allelic PRF1 mutations are extremely rare, and bone marrow reconstitutions make meaningful follow-up studies on PRF biology impossible. However, in a breakthrough study, Clementi et al. ${ }^{76}$ investigated the presence of PRF mutations in a group of 29 primary lymphoma patients and found four individuals with bi-allelic PRF1 mutations, all of who developed cancer beyond the age of 7 years. As indicated above, FHL2 onset is bimodal, and some patients with missense mutations present with the disease in their teens and even much later in their life. ${ }^{3}$ However, the mechanisms behind such a delay remained unknown.

Recently, we assessed mutant PRF function in a cohort of patients with atypical or delayed FHL. ${ }^{10}$ Thus, we identified unrelated clinical cases, in which FHL was delayed for at least 10 years, or in which the presentation of PRF dysfunction was other than with FHL. We found that almost $50 \%$ presented with $\mathrm{B}$ - or T-cell lymphoma or acute or chronic leukemia, and commonly displayed $\mathrm{FHL}$ late or not at all. The broad range of pathologies strongly suggested that a common environmental or viral cause was not responsible for the disease. This frequency of hematological cancers was over 100 times higher than what is reported in the general population, arguing strongly in favor of a critical role for PRF in the immune surveillance of cancer. Furthermore, as PRF affects only CL function, this strongly suggests that deficiency in CL function has a critical role in increased cancer incidence.

Why do cancer-prone carriers of bi-allelic PRF1 mutations manage to evade FHL early in life? Recently, our own molecular studies have shed light on this puzzling issue. Our initial analysis suggested that all but 3 of 17 cancer-and late FHL-associated PRF mutants had no cytotoxic function when analyzed in vitro. However we also discovered, through mapping these mutations onto the predicted three dimension PRF structure (based on three crystallized MACPF proteins $^{31-33}$ ) that many of the mutants localized to a single subdomain at the top of the PRF monomer, the part furthest removed from the membrane-binding domains. ${ }^{10}$ Intriguingly, in light of previous studies on $\mathrm{A} 91 \mathrm{~V},{ }^{80}$ this common variant was also shown to map to the same subdomain and result in protein misfolding. The predicted similarity between bacterial CDCs and MACPF proteins strongly suggested that PRF pore formation would require major conformational changes, which would only be possible in structurally labile proteins. ${ }^{30} \mathrm{We}$ therefore hypothesized that cancer-associated mutations, such as $\mathrm{A} 91 \mathrm{~V}$, might predominantly result in misfolding rather than loss of function per se. Indeed, by reducing the culture temperature of mutant PRF-expressing cells to $30^{\circ} \mathrm{C}$ to optimize folding, we showed that the activity of most of the mutants could be restored to a significant extent. By contrast, missense mutations that still had unrecoverable function at

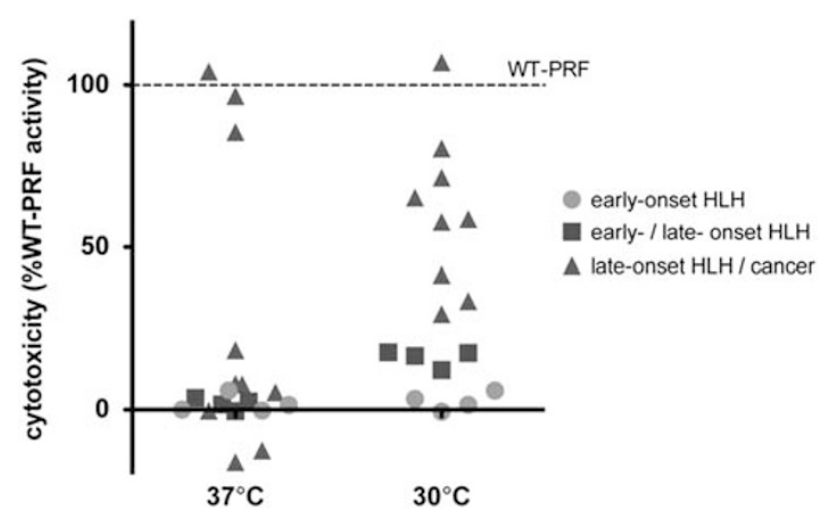

Figure 2 Temperature sensitivity of PRF mutants can predict the severity and age of onset of disease. At $37^{\circ} \mathrm{C}, \mathrm{PRF} 1$ mutations associated with disease result in a varied range of reduced cytotoxic levels compared with wild-type PRF, with a complete loss of activity for most mutations. At $30^{\circ} \mathrm{C}$, mutations consistently associated with late-onset FHL and/or various hematological cancers show greater recovery of cytotoxicity, whereas mutations that show no recovery of function are invariably associated with early-onset FHL. Mutants with intermediate levels of activity at reduced temperatures are associated both with cases of early and late-onset $\mathrm{FHL}$

this permissive temperature were invariably associated with the more common and severe FHL2 presentation in early infancy. ${ }^{10}$ Hence, it seems that temperature sensitivity of mutant PRF function can predict the severity and age-of-onset of FHL2 (Figure 2). In addition, partial PRF deficiency may unmask a predisposition to hematological cancer by extending a subject's lifespan owing to escape from the most serious consequence, FHL.

A further critical question concerns the significance of temperature sensitivity of PRF mutants, as many of these variants seemed to be non-functional at $37^{\circ} \mathrm{C}$. The answer to this question may be gleaned from the thermodynamics of protein folding, in which a correctly folded native polypeptide acquires the most stable conformation that minimizes its free energy. In the case of labile proteins such as PRF, it appears that even subtle structural changes may dictate the adoption of a correctly folded or misfolded state. Therefore, a reduction of temperature may increase the chance of a mutated protein to acquire a native folded state (Figure 3). The fact that every patient presenting with delayed $\mathrm{FHL}$ or an alternative pathology in our study carried at least one temperature-sensitive mutation further supports this notion. The most important outcome of our study was that temperature-sensitive PRF mutants were not truly null, but hypomorphic. Under physiological conditions, the correct folding of a small amount of protein would provide sufficient cytotoxic activity for survival beyond infancy and into adolescence. Other diseases have been described, in which a small amount of correctly folded mutant protein (or 'leaky' phenotype) resulted in milder symptoms of a disease. ${ }^{86}$ However, never has such a large number of naturally occurring mutants been found to be temperature sensitive as with PRF. Together, these studies make a strong case for a link between defective PRF-mediated cytotoxicity and impaired CL function and cancer susceptibility in humans (Figure 4). 


$$
\begin{aligned}
& \text { folded protein } \\
& \text { unfolded protein } \\
& \text { simple glycosylation } \\
& \text { complex glycosylation }
\end{aligned}
$$

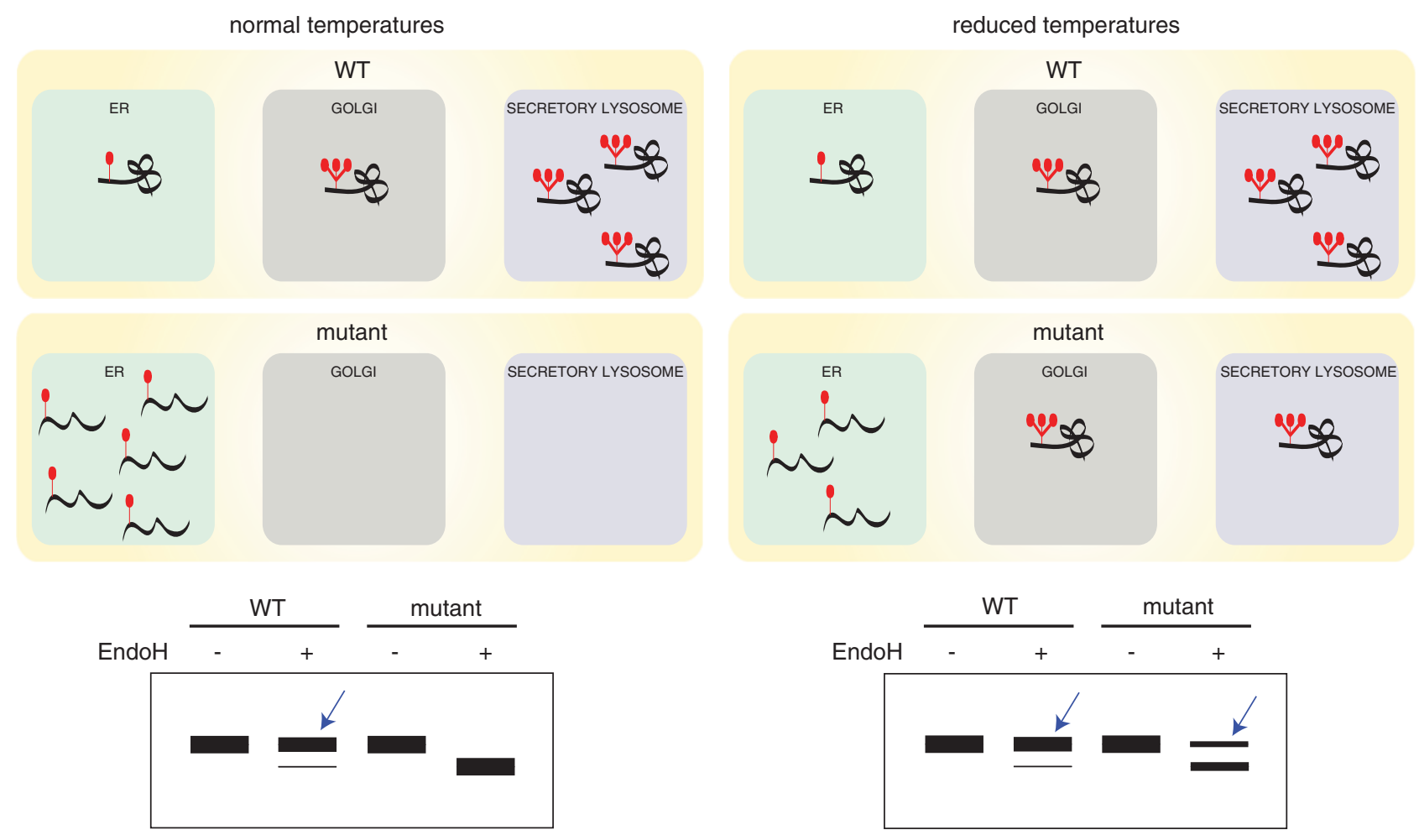

Figure 3 A proportion of molecules of temperature-sensitive perforin mutants can acquire wild-type conformation, traffic to secretory granules and offer some cytotoxic function to CL. PRF trafficking can be assessed by estimating EndoH glycosidase resistance of PRF. Such a resistance is the indicator of PRF trafficking through the Golgi compartment, wherein it acquires EndoH-insensitive complex glycosylation

\section{The Double-Edged Sword of Perforin Function}

Although all the evidence provided thus far clearly favors an essential role for PRF in immune homeostasis and immune surveillance against viruses and cancer, PRF-dependent cytotoxicity can also be dangerous if CLs turn against their host. Type 1 juvenile diabetes is an autoimmune disease in which CD8 ${ }^{+}$CTLs eliminate insulin-producing $\beta$-cells in the pancreas. Two independent studies have shown that nonobese diabetic (NOD) mice on $P R F 1^{-1}$ background had a markedly delayed onset of diabetes or did not develop the disease at all. Furthermore, NOD mice bred onto a $P R F 1^{-/+}$ background were partially resistant to the disease ${ }^{87,88}$ On the other hand, the Fas death pathway is also critically important, but it seems to play a 'priming' role in the NOD model, as FasL-deficient mice $(\mathrm{g} / \mathrm{d})$ fail to develop islet-cell inflammation altogether. ${ }^{89}$ Therefore, the coordinated action of the Fas and PRF-dependent pathways is responsible for spontaneous type 1 diabetes in mice.

Surprisingly, another disease whose manifestations are augmented by $\mathrm{CD}^{+}$CTLs is cerebral malaria. Even though the exact mechanism that drives CTLs to the brain and leads to disruption of the blood-brain barrier is yet to be fully understood, the role of PRF in this process has been well demonstrated in several independent studies in the Plasmodium berghei mouse model. The number of braininfiltrating activated CTLs was not different between the wild-type and $P R F 1^{-1-}$ mice. However, unlike wild-type mice, the knockout animals failed to develop vascular leakage in the brain, resulting in markedly reduced cerebral inflammation and edema. ${ }^{90,91}$ Given that cerebral complications are the main cause of death among malaria-infected children, designing therapeutic strategies aimed at downregulating CTL function in the brain may be highly beneficial.

Finally, a potential link between PRF1 mutations and multiple sclerosis has been recently postulated in a population study. ${ }^{92}$ As CTL infiltrates within multiple sclerosis lesions in the brain are thought to potentially contribute to the onset and progress of the disease, the downregulation of CL activity would be expected to moderate, rather than augment the disease progression. Instead, a higher proportion of patients with heterozygous A91V mutation, compared with healthy 


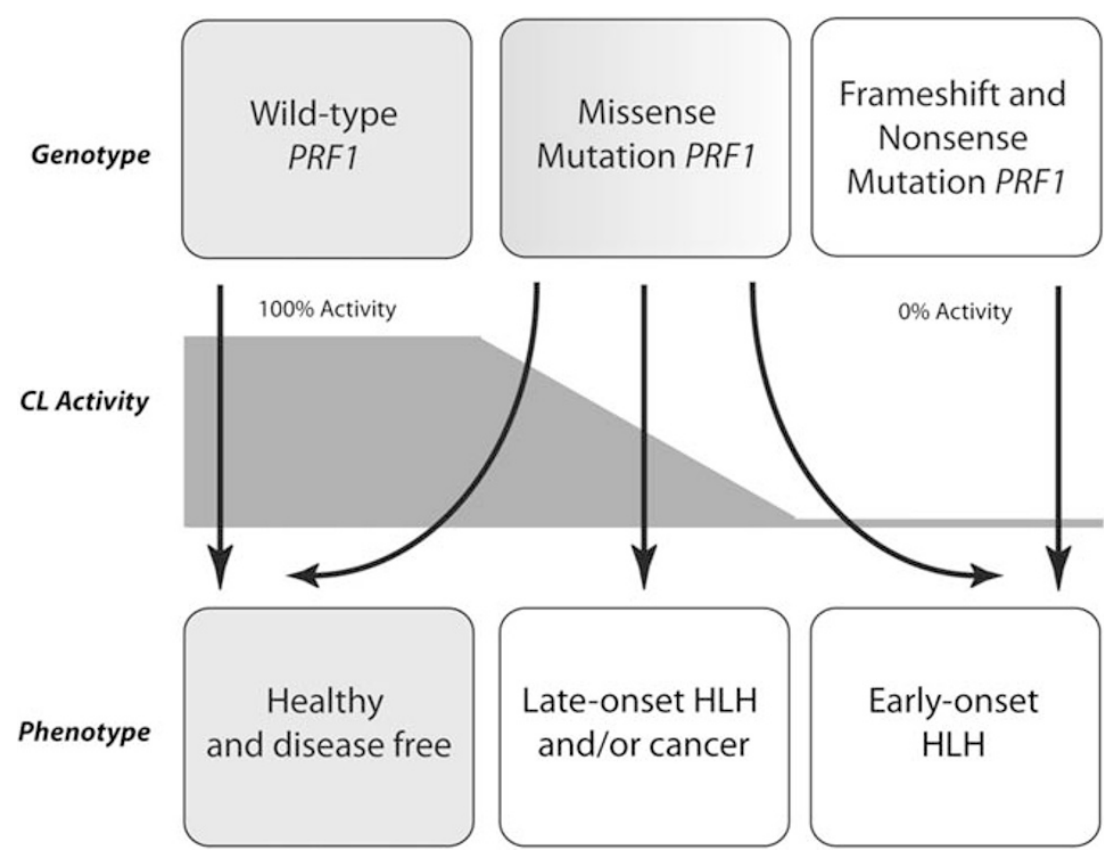

Figure 4 The genotype of PRF1 determines the phenotype of disease. Whereas nonsense and frameshift mutations of PRF1 invariably lead to early-onset FHL, missense mutations manifest in a variety of phenotypes, depending on the effect of mutations on PRF and, consequently, on $\mathrm{CL}$ activity. Some missense mutations can result in early-onset FHL, whereas others may enable escape from early-onset FHL but lead to the development of late-onset FHL or various hematological malignancies later in life

controls, were noted. Although the difference was modest, yet statistically significant, it might suggest that poorer clearance of putative underlying viral infection(s) rather than autoimmunity influences the development of the disease. ${ }^{93}$

\section{Concluding Remarks}

Over the last quarter of a century, some monumental efforts have been made to understand the biology of CLs, which evolved to adapt their killing machinery to ever-changing viral challenges and spontaneous pre-cancerous transformations. Granzymes, the key inducers of target-cell apoptosis, co-evolved with these challenges to cover a remarkable range of cellular substrates and thereby minimizing the chance of immune escape. By contrast, the fundamentals of PRF structure and mechanism were not subjected to such pressure, as its function was uniquely inherited from primordial ancestors. As such, PRF is a sole guardian of CLs and the modulation of its function has an immediate effect on cell function and the surveillance of infections and cancer. Better understanding and control of function and expression of PRF and other key granule proteins will widen the perspective of efficient diagnostics and management of immune-mediated disease.

\section{Conflict of interest}

The authors declare no conflict of interest.

1. Kagi D, Vignaux F, Ledermann B, Burki K, Depraetere V, Nagata S et al. Fas and perforin pathways as major mechanisms of T cell-mediated cytotoxicity. Science 1994; 265: 528-530

2. Trapani JA, Smyth MJ. Functional significance of the perforin/granzyme cell death pathway. Nat Rev Immunol 2002; 2: 735-747.
3. Voskoboinik I, Smyth MJ, Trapani JA. Perforin-mediated target-cell death and immune homeostasis. Nat Rev Immunol 2006; 6: 940-952.

4. Uellner R, Zvelebil MJ, Hopkins J, Jones J, MacDougall LK, Morgan BP et al. Perforin is activated by a proteolytic cleavage during biosynthesis which reveals a phospholipidbinding C2 domain. EMBO J 1997; 16: 7287-7296.

5. Voskoboinik I, Thia MC, Fletcher J, Ciccone A, Browne K, Smyth MJ et al. Calciumdependent plasma membrane binding and cell lysis by perforin are mediated through its $\mathrm{C} 2$ domain: a critical role for aspartate residues $429,435,483$, and 485 but not 491 . J Biol Chem 2005; 280: 8426-8434.

6. Mullbacher A, Waring P, ThaHla R, Tran T, Chin S, Stehle T et al. Granzymes are the essential downstream effector molecules for the control of primary virus infections by cytolytic leukocytes. Proc Natl Acad Sci USA 1999; 96: 13950-13955.

7. Nakajima H, Park HL, Henkart PA. Synergistic roles of granzymes A and B in mediating target cell death by rat basophilic leukemia mast cell tumors also expressing cytolysin/ perforin. J Exp Med 1995; 181: 1037-1046.

8. Shi L, Mai S, Israels S, Browne K, Trapani JA, Greenberg AH. Granzyme B (GraB) autonomously crosses the cell membrane and perforin initiates apoptosis and GraB nuclear localization. J Exp Med 1997; 185: 855-866.

9. Stepp SE, Dufourcq-Lagelouse R, Le Deist F, Bhawan S, Certain S, Mathew PA et al. Perforin gene defects in familial hemophagocytic lymphohistiocytosis. Science 1999; 286: 1957-1959.

10. Chia J, Yeo KP, Whisstock JC, Dunstone MA, Trapani JA, Voskoboinik I. Temperature sensitivity of human perforin mutants unmasks subtotal loss of cytotoxicity, delayed FHL, and a predisposition to cancer. Proc Natl Acad Sci USA 2009; 106: 9809-9814.

11. Pipkin ME, Ljutic B, Cruz-Guilloty F, Nouzova M, Rao A, Zuniga-Pflucker JC et al. Chromosome transfer activates and delineates a locus control region for perforin. Immunity 2007; 26: 29-41.

12. Hernandez-Pigeon $\mathrm{H}$, Jean $\mathrm{C}$, Charruyer $\mathrm{A}$, Haure MJ, Baudouin $\mathrm{C}$, Charveron $\mathrm{M}$ et al. UVA induces granzyme $B$ in human keratinocytes through MIF: implication in extracellular matrix remodeling. J Biol Chem 2007; 282: 8157-8164.

13. Hernandez-Pigeon $\mathrm{H}$, Jean $\mathrm{C}$, Charruyer A, Haure MJ, Titeux M, Tonasso L et al. Human keratinocytes acquire cellular cytotoxicity under UV-B irradiation. Implication of granzyme B and perforin. J Biol Chem 2006; 281: 13525-13532.

14. Podack ER, Dennert $G$. Assembly of two types of tubules with putative cytolytic function by cloned natural killer cells. Nature 1983; 302: 442-445.

15. Podack ER, Young JD, Cohn ZA. Isolation and biochemical and functional characterization of perforin 1 from cytolytic T-cell granules. Proc Natl Acad Sci USA 1985; 82: 8629-8633.

16. Young JD, Cohn ZA, Podack ER. The ninth component of complement and the poreforming protein (perforin 1) from cytotoxic T cells: structural, immunological, and functional similarities. Science 1986; 233: 184-190. 
17. Young JD, Hengartner H, Podack ER, Cohn ZA. Purification and characterization of a cytolytic pore-forming protein from granules of cloned lymphocytes with natural killer activity. Cell 1986; 44: 849-859.

18. Lowrey DM, Aebischer T, Olsen K, Lichtenheld M, Rupp F, Hengartner $\mathrm{H}$ et al. Cloning, analysis, and expression of murine perforin $1 \mathrm{CDNA}$, a component of cytolytic T-cell granules with homology to complement component C9. Proc Natl Acad Sci USA 1989; 86: 247-251.

19. Shinkai Y, Takio K, Okumura K. Homology of perforin to the ninth component of complement (C9). Nature 1988; 334: 525-527.

20. Tschopp J, Masson D, Stanley KK. Structural/functional similarity between proteins involved in complement- and cytotoxic T-lymphocyte-mediated cytolysis. Nature 1986; $\mathbf{3 2 2}$ : 831-834.

21. Lichtenheld MG, Olsen KJ, Lu P, Lowrey DM, Hameed A, Hengartner H et al. Structure and function of human perforin. Nature 1988; 335: 448-451.

22. Blumenthal R, Millard PJ, Henkart MP, Reynolds CW, Henkart PA. Liposomes as targets for granule cytolysin from cytotoxic large granular lymphocyte tumors. Proc Natl Acad Sci USA 1984; 81: 5551-5555.

23. Henkart PA, Yue CC, Yang J, Rosenberg SA. Cytolytic and biochemical properties of cytoplasmic granules of murine lymphokine-activated killer cells. J Immunol 1986; 137: 2611-2617.

24. Pham CT, Ley TJ. Dipeptidyl peptidase I is required for the processing and activation of granzymes A and B in vivo. Proc Natl Acad Sci USA 1999; 96: 8627-8632.

25. Smyth MJ, McGuire MJ, Thia KY. Expression of recombinant human granzyme B. A processing and activation role for dipeptidyl peptidase I. J Immunol 1995; 154: 6299-6305.

26. Bird $\mathrm{CH}$, Sutton VR, Sun J, Hirst CE, Novak A, Kumar $\mathrm{S}$ et al. Selective regulation of apoptosis: the cytotoxic lymphocyte serpin proteinase inhibitor 9 protects against granzyme B-mediated apoptosis without perturbing the Fas cell death pathway. Mol Cell Biol 1998; 18: $6387-6398$.

27. Sun J, Ooms L, Bird CH, Sutton VR, Trapani JA, Bird PI. A new family of 10 murine ovalbumin serpins includes two homologs of proteinase inhibitor 8 and two homologs of the granzyme B inhibitor (proteinase inhibitor 9). J Biol Chem 1997; 272: 15434-15441.

28. Sun J, Bird CH, Sutton V, McDonald L, Coughlin PB, De Jong TA et al. A cytosolic granzyme $B$ inhibitor related to the viral apoptotic regulator cytokine response modifier $A$ is present in cytotoxic lymphocytes. J Biol Chem 1996; 271: 27802-27809.

29. Hirst CE, Buzza MS, Bird CH, Warren HS, Cameron PU, Zhang M et al. The intracellular granzyme $B$ inhibitor, proteinase inhibitor 9 , is up-regulated during accessory cell maturation and effector cell degranulation, and its overexpression enhances CTL potency. J Immunol 2003; 170: 805-815.

30. Rosado CJ, Kondos S, Bull TE, Kuiper MJ, Law RH, Buckle AM et al. The MACPF/CDC family of pore-forming toxins. Cell Microbiol 2008; 10: 1765-1774.

31. Hadders MA, Beringer DX, Gros P. Structure of C8alpha-MACPF reveals mechanism of membrane attack in complement immune defense. Science 2007; 317: 1552-1554.

32. Rosado CJ, Buckle AM, Law RH, Butcher RE, Kan WT, Bird CH et al. A common fold mediates vertebrate defense and bacterial attack. Science 2007; 317: 1548-1551.

33. Slade DJ, Lovelace LL, Chruszcz M, Minor W, Lebioda L, Sodetz JM. Crystal structure of the MACPF domain of human complement protein $\mathrm{C} 8$ alpha in complex with the $\mathrm{C} 8$ gamma subunit. J Mol Biol 2008; 379: 331-342.

34. Baran K, Dunstone M, Chia J, Ciccone A, Browne KA, Clarke CJP et al. The molecular basis for perforin oligomerization and transmembrane pore assembly. Immunity 2009; 30 : 684-695.

35. Kagi D, Ledermann B, Burki K, Seiler P, Odermatt B, Olsen KJ et al. Cytotoxicity mediated by $T$ cells and natural killer cells is greatly impaired in perforin-deficient mice. Nature 1994; 369: 31-37.

36. Smyth MJ, Thia KY, Street SE, MacGregor D, Godfrey DI, Trapani JA. Perforin-mediated cytotoxicity is critical for surveillance of spontaneous lymphoma. J Exp Med 2000; 192: 755-760.

37. Badovinac VP, Hamilton SE, Harty JT. Viral infection results in massive CD8+ T cell expansion and mortality in vaccinated perforin-deficient mice. Immunity 2003; 18: 463-474.

38. Binder D, van den Broek MF, Kagi D, Bluethmann H, Fehr J, Hengartner $\mathrm{H}$ et al. Aplastic anemia rescued by exhaustion of cytokine-secreting CD8+ T cells in persistent infection with lymphocytic choriomeningitis virus. J Exp Med 1998; 187: 1903-1920.

39. Kagi D, Seiler P, Pavlovic J, Ledermann B, Burki K, Zinkernagel RM et al. The roles of perforin- and Fas-dependent cytotoxicity in protection against cytopathic and noncytopathic viruses. Eur J Immunol 1995; 25: 3256-3262.

40. Walsh CM, Matloubian M, Liu CC, Ueda R, Kurahara CG, Christensen JL et al. Immune function in mice lacking the perforin gene. Proc Natl Acad Sci USA 1994; 91 : 10854-10858.

41. Jordan MB, Hildeman D, Kappler J, Marrack P. An animal model of hemophagocytic lymphohistiocytosis $(\mathrm{HLH})$ : CD8+ T cells and interferon gamma are essential for the disorder. Blood 2004; 104: 735-743.

42. Ebnet K, Hausmann M, Lehmann-Grube F, Mullbacher A, Kopf M, Lamers $M$ et al Granzyme A-deficient mice retain potent cell-mediated cytotoxicity. EMBO J 1995; 14: 4230-4239.

43. Mullbacher A, Ebnet K, Blanden RV, Hla RT, Stehle T, Museteanu C et al. Granzyme A is critical for recovery of mice from infection with the natural cytopathic viral pathogen, ectromelia. Proc Natl Acad Sci USA 1996; 93: 5783-5787.
44. Simon MM, Hausmann M, Tran T, Ebnet $\mathrm{K}$, Tschopp J, ThaHla $\mathrm{R}$ et al. In vitro- and ex vivoderived cytolytic leukocytes from granzyme A x B double knockout mice are defective in granule-mediated apoptosis but not lysis of target cells. J Exp Med 1997; 186: 1781-1786.

45. Andrade F, Fellows E, Jenne DE, Rosen A, Young CS. Granzyme H destroys the function of critical adenoviral proteins required for viral DNA replication and granzyme $B$ inhibition. EMBO J 2007; 26: 2148-2157.

46. Romero V, Fellows $\mathrm{E}$, Jenne $\mathrm{DE}$, Andrade $\mathrm{F}$. Cleavage of La protein by granzyme $\mathrm{H}$ induces cytoplasmic translocation and interferes with La-mediated HCV-IRES translational activity. Cell Death Differ 2009; 16: 340-348.

47. Thia KY, Trapani JA. The granzyme B gene is highly polymorphic in wild mice but essentially invariant in common inbred laboratory strains. Tissue Antigens 2007; 70: 198-204.

48. van den Broek ME, Kagi D, Ossendorp F, Toes R, Vamvakas S, Lutz WK et al. Decreased tumor surveillance in perforin-deficient mice. J Exp Med 1996; 184: 1781-1790.

49. Smyth MJ, Thia KY, Cretney E, Kelly JM, Snook MB, Forbes CA et al. Perforin is a major contributor to NK cell control of tumor metastasis. J Immunol 1999; 162: 6658-6662.

50. Davis JE, Smyth MJ, Trapani JA. Granzyme A and B-deficient killer lymphocytes are defective in eliciting DNA fragmentation but retain potent in vivo anti-tumor capacity. Eur $J$ Immunol 2001; 31: 39-47.

51. Street SE, Cretney E, Smyth MJ. Perforin and interferon-gamma activities independently control tumor initiation, growth, and metastasis. Blood 2001; 97: 192-197.

52. Dunn GP, Bruce AT, Ikeda H, Old LJ, Schreiber RD. Cancer immunoediting: from immunosurveillance to tumor escape. Nat Immunol 2002; 3: 991-998.

53. Street SE, Trapani JA, MacGregor D, Smyth MJ. Suppression of lymphoma and epithelial malignancies effected by interferon gamma. J Exp Med 2002; 196: 129-134.

54. Smyth MJ, Street SE, Trapani JA. Cutting edge: granzymes A and B are not essential for perforin-mediated tumor rejection. J Immunol 2003; 171: 515-518.

55. Street SE, Hayakawa Y, Zhan Y, Lew AM, MacGregor D, Jamieson AM et al. Innate immune surveillance of spontaneous B cell lymphomas by natural killer cells and gammadelta T cells. J Exp Med 2004; 199: 879-884.

56. Koebel CM, Vermi W, Swann JB, Zerafa N, Rodig SJ, Old LJ et al. Adaptive immunity maintains occult cancer in an equilibrium state. Nature 2007; 450: 903-908.

57. Crowe NY, Smyth MJ, Godfrey DI. A critical role for natural killer T cells in immunosurveillance of methylcholanthrene-induced sarcomas. J Exp Med 2002; 196: 119-127.

58. Molleran Lee S, Villanueva J, Sumegi J, Zhang K, Kogawa K, Davis J et al. Characterisation of diverse PRF1 mutations leading to decreased natural killer cell activity in North American families with haemophagocytic lymphohistiocytosis. J Med Genet 2004; 41: 137-144

59. Henter JI, Elinder G. Familial hemophagocytic lymphohistiocytosis. Clinical review based on the findings in seven children. Acta Paediatr Scand 1991; 80: 269-277.

60. Janka GE. Familial and acquired hemophagocytic lymphohistiocytosis. Eur J Pediatr 2007; 166: 95-109.

61. Filipovich AH. Hemophagocytic lymphohistiocytosis and other hemophagocytic disorders. Immunol Allergy Clin North Am 2008; 28: 293-313.

62. Feldmann J, Callebaut I, Raposo G, Certain S, Bacq D, Dumont C et al. Munc13-4 is essential for cytolytic granules fusion and is mutated in a form of familial hemophagocytic lymphohistiocytosis (FHL3). Cell 2003; 115: 461-473.

63. Menager MM, Menasche G, Romao M, Knapnougel P, Ho CH, Garfa M et al. Secretory cytotoxic granule maturation and exocytosis require the effector protein hMunc13-4. Nat Immunol 2007; 8: 257-267.

64. Cote M, Menager MM, Burgess A, Mahlaoui N, Picard C, Schaffner C et al. Munc18-2 deficiency causes familial hemophagocytic lymphohistiocytosis type 5 and impairs cytotoxic granule exocytosis in patient NK cells. J Clin Invest 2009; 119: 3765-3773.

65. zur Stadt U, Rohr J, Seifert W, Koch F, Grieve S, Pagel J et al. Familial hemophagocytic lymphohistiocytosis type 5 (FHL-5) is caused by mutations in Munc18-2 and impaired binding to syntaxin 11. Am J Hum Genet 2009; 85: 482-492.

66. Bryceson YT, Rudd E, Zheng C, Edner J, Ma D, Wood SM et al. Defective cytotoxic lymphocyte degranulation in syntaxin-11 deficient familial hemophagocytic lymphohistiocytosis 4 (FHL4) patients. Blood 2007; 110: 1906-1915.

67. Ishii E, Ohga S, Imashuku S, Kimura N, Ueda I, Morimoto A et al. Review of hemophagocytic lymphohistiocytosis $(\mathrm{HLH})$ in children with focus on Japanese experiences. Crit Rev Oncol Hematol 2005; 53: 209-223.

68. Zur Stadt U, Beutel K, Kolberg S, Schneppenheim R, Kabisch H, Janka G et al. Mutation spectrum in children with primary hemophagocytic lymphohistiocytosis: molecular and functional analyses of PRF1, UNC13D, STX11, and RAB27A. Hum Mutat 2006; 27: 62-68.

69. Trizzino A, zur Stadt U, Ueda I, Risma K, Janka G, Ishii E et al. Genotype-phenotype study of familial haemophagocytic lymphohistiocytosis due to perforin mutations. J Med Genet 2008; 45: 15-21.

70. Lee SM, Sumegi J, Villanueva J, Tabata Y, Zhang K, Chakraborty R et al. Patients of African ancestry with hemophagocytic lymphohistiocytosis share a common haplotype of PRF1 with a 50delT mutation. J Pediatr 2006; 149: 134-137.

71. Ueda I, Morimoto A, Inaba T, Yagi T, Hibi S, Sugimoto T et al. Characteristic perforin gene mutations of haemophagocytic lymphohistiocytosis patients in Japan. Br J Haematol 2003; 121: 503-510.

72. Mehta PA, Davies SM, Kumar A, Devidas M, Lee S, Zamzow T et al. Perforin polymorphism A91V and susceptibility to B-precursor childhood acute lymphoblastic leukemia: a report from the Children's Oncology Group. Leukemia 2006; 20: 1539-1541. 
73. Santoro A, Cannella S, Trizzino A, Lo Nigro L, Corsello G, Arico M. A single amino acid change A91V in perforin: a novel, frequent predisposing factor to childhood acute lymphoblastic leukemia? Haematologica 2005; 90: 697-698.

74. Zur Stadt U, Beutel K, Weber B, Kabisch H, Schneppenheim R, Janka G et al. A91V is a polymorphism in the perforin gene not causative of an FHLH phenotype. Blood 2004; 104 1909-1910.

75. Muralitharan S, Wali Y, Pathare AV. Perforin A91V polymorphism and putative susceptibility to hematological malignancies. Leukemia 2006; 20: 2178.

76. Clementi R, Locatelli F, Dupre L, Garaventa A, Emmi L, Bregni M et al. A proportion of patients with lymphoma may harbor mutations of the perforin gene. Blood 2005; 105: 4424-4428.

77. Cannella S, Santoro A, Bruno G, Pillon M, Mussolin L, Mangili G et al. Germline mutations of the perforin gene are a frequent occurrence in childhood anaplastic large cell lymphoma. Cancer 2007; 109: 2566-2571.

78. Clementi R, Chiocchetti A, Cappellano G, Cerutti E, Ferretti M, Orilieri E et al. Variations of the perforin gene in patients with autoimmunity/lymphoproliferation and defective fas function. Blood 2006; 108: 3079-3084.

79. Voskoboinik I, Thia MC, Trapani JA. A functional analysis of the putative polymorphism A91V and N252S and 22 missense perforin mutations associated with familial hemophagocytic lymphohistiocytosis. Blood 2005; 105: 4700-4706.

80. Voskoboinik I, Sutton VR, Ciccone A, House CM, Chia J, Darcy PK et al. Perforin activity and immune homeostasis: the common A91V polymorphism in perforin results in both presynaptic and postsynaptic defects in function. Blood 2007; 110: 1184-1190.

81. Trambas C, Gallo F, Pende D, Marcenaro S, Moretta L, De Fusco C et al. A single amino acid change, A91V, leads to conformational changes that can impair processing to the active form of perforin. Blood 2005; 106: 932-937.

82. Henter Jl, Horne A, Arico M, Egeler RM, Filipovich AH, Imashuku S et al. HLH-2004: diagnostic and therapeutic guidelines for hemophagocytic lymphohistiocytosis. Pediatr Blood Cancer 2007; 48: 124-131.

83. Mancebo E, Allende LM, Guzman M, Paz-Artal E, Gil J, Urrea-Moreno R et al. Familia hemophagocytic lymphohistiocytosis in an adult patient homozygous for A91V in the perforin gene, with tuberculosis infection. Haematologica 2006; 91: 1257-1260.
84. Nagafuji K, Nonami A, Kumano T, Kikushige Y, Yoshimoto G, Takenaka K et al. Perforin gene mutations in adult-onset hemophagocytic lymphohistiocytosis. Haematologica 2007; 92: $978-981$.

85. Imai K, Matsuyama S, Miyake S, Suga K, Nakachi K. Natural cytotoxic activity of peripheral-blood lymphocytes and cancer incidence: an 11-year follow-up study of a general population. Lancet 2000; 356: 1795-1799.

86. Denning MG, Anderson MP, Amara JF, Marshall J, Smith AE, Welsh MJ. Processing of mutant cystic fibrosis transmembrane conductance regulator is temperature-sensitive. Nature 1992; 358: 761-764.

87. Kagi D, Odermatt B, Ohashi PS, Zinkernagel RM, Hengartner $H$. Development of insulitis without diabetes in transgenic mice lacking perforin-dependent cytotoxicity. J Exp Med 1996; 183: 2143-2152.

88. Kagi D, Odermatt B, Seiler P, Zinkernagel RM, Mak TW, Hengartner H. Reduced incidence and delayed onset of diabetes in perforin-deficient nonobese diabetic mice. $J$ Exp Med 1997; 186: 989-997.

89. Su X, Hu Q, Kristan JM, Costa C, Shen Y, Gero D et al. Significant role for Fas in the pathogenesis of autoimmune diabetes. J Immunol 2000; 164: 2523-2532.

90. Potter S, Chan-Ling T, Ball HJ, Mansour H, Mitchell A, Maluish L et al. Perforin mediated apoptosis of cerebral microvascular endothelial cells during experimental cerebral malaria. Int J Parasitol 2006; 36: 485-496.

91. Nitcheu J, Bonduelle O, Combadiere C, Tefit M, Seilhean D, Mazier D et al. Perforindependent brain-infiltrating cytotoxic $\mathrm{CD} 8+\mathrm{T}$ lymphocytes mediate experimental cerebral malaria pathogenesis. J Immunol 2003; 170: 2221-2228.

92. Cappellano G, Orilieri E, Comi C, Chiocchetti A, Bocca S, Boggio E et al. Variations of the perforin gene in patients with multiple sclerosis. Genes Immun 2008; 9: 438-444.

93. Deb C, Lafrance-Corey RG, Zoecklein L, Papke L, Rodriguez M, Howe CL. Demyelinated axons and motor function are protected by genetic deletion of perforin in a mouse model of multiple sclerosis. J Neuropathol Exp Neurol 2009; 68: 1037-1048.

94. Trapani JA, Voskoboinik I. The complex issue of regulating perforin expression. Trends Immunol 2007; 28: 243-245. 